\title{
ESTIMATING INVESTMENT FUNCTIONS BASED ON COINTEGRATION: THE CASE OF CHINA
}

\section{Laixiang Sun}

International Institute for Applied Systems Analysis

Laxenburg, Austria and

Institute of Social Studies, The Hague, Netherlands

RR-98-7

July 1998

Reprinted from Journal of Comparative Economics, Volume 26, Number 1, pp. 175-191, March 1998. 
Research Reports, which record research conducted at IIASA, are independently reviewed before publication. Views or opinions expressed herein do not necessarily represent those of the Institute, its National Member Organizations, or other organizations supporting the work.

Reprinted with permission from Journal of Comparative Economics, Volume 26, Number 1, pp. 175-191, March 1998.

Copyright (c) 1998 by Academic Press, Inc.

All rights reserved. No part of this publication may be reproduced or transmitted in any form or by any means, electronic or mechanical, including photocopy, recording, or any information storage or retrieval system, without permission in writing from the copyright holder. 


\title{
Estimating Investment Functions Based on Cointegration: The Case of China ${ }^{1}$
}

\author{
Laixiang Sun \\ International Institute for Applied Systems Analysis, Laxenburg, Austria, \\ and Institute of Social Studies, the Hague, the Netherlands
}

Received November 25, 1996; revised October 15, 1997

\begin{abstract}
Sun, Laixiang - Estimating Investment Functions Based on Cointegration: The Case of China

In the Chinese context, a persistent tension exists between system-generated investment ambitions and both the supply and the distributive barriers to these ambitions. This holds for both pre- and postreform periods and across significant policy changes. As a result, the long-run investment function is characterized by equilibrium comovement among real fixed investment level, grain output per capita as representative of necessary consumer goods, and effective energy supply per capita as representative of basic producer goods. A large part of the cyclical pattern of investment growth can be explained by the adjustment to the comovement path and by the relevant changes in energy supply and agricultural output. J. Comp. Econom., March 1998, 26(1), pp. 175-191. International Institute for Applied Systems Analysis, Laxenburg, Austria, and Institute of Social Studies, the Hague, the Netherlands. (1) 1998 Academic Press
\end{abstract}

Journal of Economic Literature Classification Numbers: C51, E32, O21, P33.

\section{INTRODUCTION}

China has maintained quite high capital accumulation levels and aggregate investment ratios. ${ }^{2}$ At the same time, state-sector fixed investment, which

${ }^{1}$ I am much indebted to John Bonin, Bill Wansing Hung, Karel Jansen, Søren Johansen, Michiel Keyzer, Haris Psaradakis, Charles Rossmann, Ashwani Saith, Servaas Storm, Rob Vos, Marc Wuyts, and two anonymous referees of this journal for their help, comments, and advice.

${ }^{2}$ The average proportions of accumulation and state sector fixed investment in the National Income Used are 29.9 with a standard deviation (SD) of 6.65 and 19.5 with a SD of 5.27 during the 1953-1993 period; the same figures as a percentage of GDP are 27.6 (SD 2.45) during 1978-1993 and 18.3 (SD 2.19) during 1978-1995, when the relevant statistical figures were available (source: Statistical Yearbook of China, hereafter Yearbook, 1993, pp. 31, 43, 149; 1995, p. $137 ; 1996$, pp. 42, 139). 
accounts for a dominant share of gross fixed investment, ${ }^{3}$ has displayed conspicuous cyclical patterns in its annual growth rate. The relevant amplitudes are very impressive in comparison with those of other socialist countries, e.g., the former Soviet Union and Eastern European. ${ }^{4}$ An interesting question thus arises: which mechanisms produce such persistent high investment ratios and what forces shape the remarkable cyclical patterns of these investment growth rates?

According to the standard theory of socialist economies, the system constantly initiates pressures and incentives to maximize investment and cannot generate internally self-imposed restraint to resist expansionary drives (Kornai, 1992, Chap. 9). As a result, the realized real investment level has, on the one hand, accounted for quite a high proportion of the national income and has, on the other hand, been constrained by the supply possibilities frontier of bottleneck sectors. In the case of China, investment is limited by the tolerable adverse distributional impact it has on food supply. Against the background of significant policy change, a more interesting question is: has reform altered the investment coordination mechanism fundamentally?

Initial data analysis shows a surprising lack of structural change in stateowned industry in terms of the subsectoral shares of output, employment, and investment when compared with township- and village-run industry. This remarkable structural rigidity may imply that state-sector investment is not yet based mainly on market criteria and that the state investment system does not respond actively to the changes in demand occurring in a rapidly growing and transforming economy. This finding motivates more accurate econometric modeling and testing based on cointegration and error correction approaches.

In comparison with the traditional approach of constructing and estimating a planners' response function, ${ }^{5}$ two major advantages of cointegration analysis are worth mentioning. First, as a statistical expression of a long-run equilibrium relationship among two or more nonstationary time series, cointegration can help to establish cycle analysis based on the behavioral assumption of intertemporal rationality. The approach based on a representative planner

\footnotetext{
${ }^{3}$ The percentage shares of state-sector fixed investment are 69.5 in 1981, 65.6 in 1990, and 57.0 in 1994 (Statistical Survey of China, 1994, p. 27; Yearbook, 1996, p. 139). The fact that statistics on total fixed investment covering all ownership types started only in 1981 prevents us from dealing with the patterns of total fixed investment for the pre-1980 period.

${ }^{4}$ There are seven investment cycles in China with lengths of 3-8 years in the 1953-1995 period. The maximum and minimum values of real investment growth rates in China from 1953 to 1995 are 84.5 and $-62.5 \%$, respectively; in the former Soviet Union 18.2 and $0.7 \%$; in Hungary 36.0 and $-23.3 \%$; in Poland 25.4 and $-22.3 \%$; and in Bulgaria 51.2 and $-2.2 \%$ from 1951 to 1989, respectively (sources: for China, see Appendix; for the others, see Mihályi, 1992, p. 120).

${ }^{5}$ For an extensive survey on this subject, see Mihályi (1992). Attempts to apply such response functions to China include Naughton (1987) and Imai (1994).
} 
faces the problem of intertemporal inconsistency of the planner's rationality (Mihályi, 1992). Based on a cointegration approach, we can assume that the investment decision makers at different levels and different sectors are all rational economic agents and that, because of their own specific interests and incentives, they cannot be considered as representative planners. As a consequence, coordination mechanisms that prevail among economic agents are of decisive importance and cannot be ignored. Full information and rationality of individual choice are not sufficient to preclude the business cycle in a well-functioning market economy. The bureaucratic coordination mechanism that characterizes the state investment system of China has also failed to prevent an investment cycle.

Second, the cointegration relation presents a long-run equilibrium comovement among the real investment level, supply, and distributive barriers to investment expansion. Thus, it can replace the traditional univariate norm concept because it indicates clearly the long-run equilibrium determined by the fundamental tension between system-generated investment ambition and the supply and distributive barriers to that ambition. Moreover, such a comovement path also serves as an attractor for the disequilibrium adjustment of the investment decision makers toward a dynamic equilibrium as shown by the error-correction model.

Because the share of state-sector fixed investment has been very high and due to the data limitations noted, this paper focuses on fixed investment in the state sector only for the period of 1953-1995. For simplicity, investment hereafter refers to the state-sector fixed investment.

The paper is organized as follows. Section 2 first presents a brief analysis of the persistent investment hunger in the state sector during the reform period and then identifies the representative bottlenecks in both the consumer goods and producer goods sectors. In Section 3, the integration and cointegration properties of the data are analyzed, a long-run investment-level function and a conditional error-correction model of investment growth are presented, and the relevant weak exogeneity of the conditional variables is examined. Section 4 summarizes the results.

\section{SUPPLY AND DISTRIBUTIVE BARRIERS}

\section{TO INVESTMENT EXPANSION}

The process of investment decision-making in the state sector is a distribution process of rights to possess and use certain scarce state assets, including budget funds, bank loans, land, quotas of power, oil, and other key materials in shortage. The primary intention of ministries, local governments and firms is to obtain and occupy as much investment and other assets from the bureaucratic distribution process as possible so that they can reap future benefits and justify both their existence and their power base. A simple but insightful 
example is that of a state enterprise initially assigned a building or a piece of land in the commercial center of a city by negotiation or only by chance and making greater profits so that its employees can get more bonus simply by renting the building or land. This is the essential source of investment hunger at each level. As a consequence, when trying to establish a new investment project, the relevant decision makers usually pay only secondary attention to the future profitability of the project. It is good if the project is profitable but if it is not, the loss will be borne by the state anyway. Such an investment expansion drive, combined with the persistent soft-budget constraint (Zou and Sun, 1996), will certainly induce investment hunger and lead to inefficient allocation of investment. This consequence is well-understood by top-level Chinese planners but they have failed to address it. ${ }^{6}$ This systemgenerated investment hunger renders investment supply-constrained and is not about fine-tuning the level of investment. Rather it pushes relentlessly the economy toward overheating, thereby producing tensions that lead to subsequent error corrections.

Treating food supply as a key constraint to industrial expansion is a persistent idea in the study of developing economies. Kalecki (1976) treats the supply of foodstuffs, which he called necessities, as central to macroeconomic analysis in a developing economy, not simply an additional welfare issue. $\mathrm{He}$ interprets the problem of financing development as more than an adjustment of planned aggregate output to the available supply of necessities. His emphasis is on a distributive barrier between a rising investment rate and the requisite agricultural growth.

This distributive barrier can be further substantiated by considering China's specific accumulation mechanism because its main characteristics are coercive extraction from agriculture and forced saving through depressing real wages and consumption (Lin et al., 1996, Chap. 2; Sheng, 1993). When a mechanism for extracting agricultural resources through both undervaluing agricultural products and the use of coercion is put into effect, the immediate result is a reduction in surplus products or a decrease in labor income. Consequently, the growth rate of either agricultural production or peasants' consumption declines. When agriculture is exploited so that it loses its comparative profitability, the sector shrinks, disinvestment occurs, and real consumption levels of both the rural and the urban population fall. The continuous drop in consumption levels may induce economic, social, and political instability. Under such a situation, the only way to resolve the crisis is to readjust the distributive

\footnotetext{
${ }^{6}$ For example, in his annual report to the 1997 National People's Congress, Chen Jinhua, head of the State Planning Commission, once again blamed the poor performance of state-owned enterprises on overheated fixed investment, which led to excessive production capacity, insufficient use of facilities, low efficiency, high costs, and low competitiveness (People's Daily, March 4, 1997).
} 
pattern of national income so as to transfer some resources back into agriculture. This is the mechanism that links China's macroeconomic adjustment and related investment cycles much more closely to agricultural fluctuation than is the case in other countries.

The most important indicator for representing the agricultural situation in China is grain output per capita (GRNPC), first because of the crucial position of grain both in Chinese livelihood and in the national economy and second because grain is a relatively homogeneous, nonsubstitutable, and necessary commodity. Furthermore, its production takes up a large share of total agricultural production and it has been in a comparatively unfavorable position within the socialist price and resource allocation systems. As a consequence, the grain supply is the binding constraint on the economy and the indicator grain output per capita is a barometer of agricultural production. ${ }^{8}$ If one can identify a variable to which the decision makers are most responsive on the basis of the frequency with which phrases appear in official documents and leading articles of official newspapers, the first candidate would be "grain output per capita." In addition to its political importance, this indicator is statistically sound and relatively error free. The data are comparable directly in terms of both time series and cross-section figures; its significance is clear and readily understood by both officials and the public. By comparison, other indicators designed by economists and statisticians, such as total factor productivity or the shortage index of consumer goods market are complicated, cumbersome, and controversial. Therefore, we employ GRNPC to indicate the agricultural supply capacity to support investment expansion.

Intuitively speaking, investment goods, such as steel, cement, plate glass, and power should together or alternatively act as the direct bottleneck constraints to fixed investment. The reasons for using effective energy supply to represent comprehensively those bottlenecks are because energy includes power, gasoline, diesel fuel, coal, and other key investment goods and also because the long-lasting heavy-industry oriented development strategy has overdeveloped the producer goods sector that consequently maintains over

\footnotetext{
${ }^{7}$ Revealing such a two-way interaction between agricultural fluctuation and investment adjustment does not imply that the agricultural fluctuation is fully determined by the interactions. This interdependence provides a sound basis for modeling investment cycles in China. Other factors such as weather and market effects make the causality from agriculture to investment more significant than the reverse. Thus, the agricultural variable appears to be weakly, but not strongly, exogenous in the system of equations modeling investment cycles.

${ }^{8}$ In 1995, the production of cereals in China was at a record of 416 million tons. However, the corresponding per capita quantity was only $340 \mathrm{~kg}$, less than the 1994 world average of 348 $\mathrm{kg}$ (Yearbook, 1996, pp. 69, 371, 811; 1995, p. 770). Among the various competitive uses of grain, its direct consumption as a foodstuff by humans accounts for $70 \%$ of the total production. In 1994 a least 80 million people still suffered from a shortage of basic food (People's Daily, Feb. 4, 1995, p. 2).
} 
$20 \%$ of its equipment in idleness mainly because of the energy shortage (Lin et al., 1996, Chap. 3). Power stations frequently have to turn off generators because of coal shortages, although power shortage has been the most explicit source of trouble in the economy as manifested by frequent and unplanned electricity outages. Chinese media have reported repeatedly on factories, even steel plants, having to stop production because of power shortages, power stations having to switch off generators because of lack of coal, and transport having to cease because of oil shortages. These facts indicate clearly that, from the production side, the most significant cause of long-lasting shortage of investment goods is energy shortage. ${ }^{9}$

The energy shortage is, in turn, closely linked to a transport bottleneck. A unique feature of energy consumption in China is that coal accounts for over three-quarters of primary commercial energy consumption (Yearbook, 1995, p. 199). However, because of transport constraints, coal shortages at industrial centers and coal stocks of above-storage capacity at mining centers have coexisted in most months. Furthermore, although the government has given top priority to coal transport in railway development since 1980, the incremental gaps of coal demand over coal freight volume and of coal output over the freight volume have increased steadily. Thus, the tension between energy demand and effective supply has persisted and even been aggravated. ${ }^{10}$

Under conditions of chronic energy shortages and transport constraints, the normal stock of coal and other energy at consumption sites has remained insignificant in comparison with annual total consumption. Thus, the indicator of energy consumption is equivalent to effective energy supply in terms of annual measurement, although energy output may be significantly different from energy consumption. Consider coal consumption for power generation as an example. Coal used for power generation accounts for about $25 \%$ of the total produced (Peng, 1989). The normal coal stock in power plants that have access to the coal supply directly planned by the state is equal to their weekly consumption and thus is only $1.7 \%$ of their annual consumption. During an energy crisis, coal stocks often equal their consumption quantity for only 2 or 3 days, an amount well less than $1 \%$ of annual consumption (Liang, 1989; Zhang, 1991). Therefore, it is reasonable to take annual energy consumption as a proxy for effective energy supply.

\footnotetext{
${ }^{9}$ For relevant reports on this issue written by Chinese officials and researches, see, for example, Energy of China (Zhongguo Nengyuan) (1989, no. 2, pp. 6-9; no. 3, pp. 1-4; no. 6, pp. 31 34; 1990, no. 3, pp. 4-9; no. 5, pp. 18-21; 1991, no. 7, pp. 37-40; no. 10, pp. 5-15; 1992 , no. 2, pp. 4-5; no. 3, pp. 5-10; no. 7, pp. 23-28), China Investment and Construction (Zhongguo Touzi yu Jianshe) $(1988$, no. 8, pp. $25-27$; no. 12, pp. 18-19; 1989, no. 3, pp. 10-12). For the relevant literature in English, see Hussain (1995), Smil (1988), and World Bank (1985).

${ }^{10}$ For relevant reports on this issue, see, besides the last note, People's Daily (9 March 1989, p. 5), China Information Daily (2 July 1993, p. 1), China Investment and Construction (1992. no. 12, pp. 25-26).
} 


\section{COINTEGRATION ESTIMATION AND INVESTMENT DETERMINATION EQUATIONS}

\subsection{Modeling Approach}

Following the literature of dynamic cointegration analysis (e.g., Hendry and Mizon, 1993), the starting point of modeling a nonstationary time-series system can be an unrestricted vector autoregression (UVAR) representation in the form of error correction for all endogenous variables in the system

$$
\Delta Z_{t}=\Pi Z_{t-1}+\sum_{i=1}^{k-1} \Pi_{i} \Delta Z_{t-i}+\mu_{t}+\epsilon_{t},
$$

where $Z_{t}$ is an $(n \times 1)$ vector of $I(1)$ variables, $Z_{-k+1}, \ldots, Z_{0}$ are fixed, $\Pi$ and $\Pi_{i}(i=1, \ldots, k-1)$ are $(n \times n)$ coefficient matrixes, $\mu_{t}$ is an $(n \times 1)$ constant vector, and $\epsilon_{t}$ is independently, normally distributed with mean 0 and covariance matrix $\Omega$.

The hypothesis of cointegration is formulated as a restriction on the matrix $\Pi$, i.e., $H_{r}: \Pi=\alpha \beta^{\prime}$, where $\beta$ consists of the coefficient vectors of $r$ cointegration relationships and $\alpha$ is the relevant adjustment coefficient matrix while the other parameters are left unrestricted. Thus, we use the Gaussian fullinformation maximum likelihood (FIML) cointegration procedure proposed by Johansen and Juselius (1990) to find out the $r$ cointegrating vectors and corresponding adjustment coefficients matrix. In order to reduce model (1) into the well-known single-equation analysis, we formulate a partial system as a conditional model and discuss its properties. In other words, for $Z_{t}=$ $\left(y_{t}, X_{t}^{\prime}\right)^{\prime}$, model (1) under the cointegration hypothesis $H_{r}$ can be factorized into a conditional equation for $y_{t}$ given $X_{t}$ and a marginal model for $X_{t}$ as follows (Johansen, 1992b):

$$
\begin{gathered}
\Delta y_{t}=\omega \Delta X_{t}+\left(\alpha_{y}-\omega \alpha_{X}\right) \beta^{\prime} Z_{t-1}+\sum_{i=1}^{k-1}\left(\Pi_{y i}-\omega \Pi_{X i}\right) \Delta Z_{t-i} \\
+\mu_{y}-\omega \mu_{X}+\epsilon_{y t}-\omega \epsilon_{X t} \\
\Delta X_{t}=\alpha_{X} \beta^{\prime} Z_{t-1}+\sum_{i=1}^{k-1} \Pi_{X i} \Delta Z_{t-i}+\mu_{X}+\epsilon_{X t} .
\end{gathered}
$$

In the above, $\alpha, \Pi_{1}, \ldots, \Pi_{k-1}, \epsilon_{t}$, and $\Omega$ are decomposed correspondingly and $\omega=\Omega_{y X} \Omega_{X X}^{-1}$, the stochastic properties of the conditioning variables, are well defined. The various relevant exogeneities also become testable in the factorized system.

If the parameter vector of interest denoted $\theta$, e.g., the coefficient vector of a unique cointegration relationship or of the conditional equation in our case, is a function only of the parameters of the conditional equation and if the parameters of the conditional and marginal distributions $\left(\boldsymbol{\lambda}_{1}, \boldsymbol{\lambda}_{2}\right)$ belong to 
the product of their individual parameter spaces $\left(\Lambda_{1} \times \Lambda_{2}\right)$ and are thus variation free, the variables in $X_{t}$ are weakly exogenous for the $\theta$. A formal test of weak exogeneity for the parameter $\boldsymbol{\beta}$ in $\boldsymbol{\Pi}=\boldsymbol{\alpha} \boldsymbol{\beta}^{\prime}$ is due to Johansen (1992a) and an extended test of weak exogeneity for all of the long-run and short-run coefficients in the conditional equation as parameters of interest is given by Urbain (1992). Weak exogeneity implies that the conditional equation contains as much information as the full UVAR system about the parameters of interest in the equation. In particular, if there is only one cointegrating relation, the analysis of model (1) can be reduced to the well-known singleequation analysis. In our case, the derived conditional investment determination equation does not lose any information on the parameters of interest, i.e., both long-run and short-run coefficients in the conditional equation, when compared with the corresponding completely specified vector system (UVAR) so long as $r=1$.

\subsection{The Long-Run Investment Function}

The data set consists of annual observations of fixed investment by state sector $(I)$, the deflator of $I(P)$, a 3-year moving average of grain output per capita (GM), and energy consumption per capita $(E) .{ }^{11}$ The sample period is 1953-1995 and the appendix provides details of the data sources. Throughout lower-case letters represent natural logarithms of the corresponding capitals and $\Delta$ denotes the first-difference operator. Our sample size of 43 observations is admittedly small for integration and cointegration analyses. While attempts have been made to correct for small-sample biases, the limitations inherent in a small sample need to be borne in mind when interpreting the findings. The findings should be treated as instructive rather than definitive. On the other hand, compared with the existing research, the sample used here is one of the largest. More importantly, the results lend themselves easily to economic interpretation and exhibit well-specified and well-fitted statistical properties.

To test for the existence of autoregressive unit roots in the nondeterministic components of the individual series, the ADF procedure for $i, g m$, and $e$ and Perron's additive outlier model for $p$ are used (Dickey and Fuller, 1979; Perron, 1994). The test results suggest that $i, g m$, and $p$ appear to be $I(1) ; e$ looks like $I(0)$ with trend at the $5 \%$ level but $I(1)$ at the $1 \%$ level. Once we

\footnotetext{
${ }^{11}$ We use a lagged 3-year $(t, t-1, t-2)$ moving average of grain output per capita because at least 2 or 3 years of consecutive good (bad) harvests can create expectations that the bottleneck of agriculture has been significantly relieved (narrowed). Hence, either investment booming is guaranteed or contraction is urged. However, a single good (bad) harvest alone is not sufficient to stimulate such expectations.
} 
investigate the joint integration properties of the data by UVAR cointegration analysis, all of them appear to be $I(1)$ processes. ${ }^{12}$

In order to examine the cointegration property of the basic system $(i, e$, $g m, p)$, the Gaussian FIML cointegration procedure proposed by Johansen and Juselius (1990) is applied. The dimension of the cointegration space could be determined by means of maximal eigenvalue $\left(\lambda_{\max }\right)$ and trace $\left(\lambda_{\text {trace }}\right)$ likelihood ratio (LR) test statistics. However, in the case of a small sample, the Johansen procedure may overreject a true null, as pointed out by Reimers (1992). Thus, we employ Reimers' small-sample correction by using ( $T-$ $n k) \log \left(1-\lambda_{i}\right)$ instead of $T \log \left(1-\lambda_{i}\right)$ for the test statistics, which typically improves the properties of LR tests for cointegration in moderately sized samples. The test outcomes with $k=2$ and a restricted constant are presented in Table 1. They indicate that we can reject $r=0$ at the 5\% level and accept the other hypotheses. The graphic test for cointegration relations (Fig. 1) shows that the relationship $\boldsymbol{\beta}^{\prime}\left(Z_{t}^{\prime} 1\right)^{\prime}$, which corresponds to the first eigenvector, $\boldsymbol{\beta}$, in Table 1, looks fairly stationary but all of the others appear to be distinctly nonstationary. Based on these findings we proceed on the assumption that we have one cointegration vector and three unit roots.

Table 1 also reports the standardized eigenvectors and the corresponding adjustment coefficient vectors derived from the maximization of the likelihood function of model (1). The cointegration vector $\boldsymbol{\beta}$ will characterize a long-run solution to an investment determination equation if the relevant cointegration relation is homogeneous of degree one in $p$. Table 2 presents the results of testing for unitary elasticity of energy per capita, price homogeneity of degree one, and double elasticity of grain output per capita, along with the clarified long-run investment determination relation. These tests are based on the Johansen and Juselius (1992) LR tests of linear restrictions on $\boldsymbol{\beta}$. The results suggest that we should accept the following well-performed long-run investment function for China: ${ }^{13}$

$$
i-p=e+2.0 g m+13.74 \text {. }
$$

Equation (4) indicates that the long-run real investment level in China has

\footnotetext{
${ }^{12}$ The misspecification tests for model (1) are not reported here to save space. The results can be obtained from the author by request.

${ }^{13}$ In order to confirm this result for readers who prefer explicit standard errors presented together with the estimated equation, an unrestricted autoregressive distributed lag of $i$ on $p, e$, and gm with two successive lags has also been estimated. The solved static long-run solution is

$$
\begin{array}{r}
i=1.19 p+1.01 e+1.95 g m+13.48, \\
(0.11) \quad(0.06) \quad(0.27) \quad(1.36)
\end{array}
$$

which is not different statistically from Eq. (4). However, Eq. (4) given before is based on the Johansen procedure and demonstrates empirically the cointegration property of the basic system.
} 
TABLE 1

The Cointegration Analysis of Model (1)

\begin{tabular}{lcccc}
\hline Hypothesis & $r=0$ & $r=1$ & $r=2$ & $r=3$ \\
\hline Eigenvalue & 0.607 & 0.425 & 0.272 & 0.160 \\
$\lambda_{\max }$ by $T$ - $n k$ & 30.85 & 18.28 & 10.50 & 5.75 \\
$95 \%$ Quantile & 28.10 & 22.00 & 15.70 & 9.20 \\
$\lambda_{\text {trace by } T \text { - } n k}$ & 65.37 & 34.52 & 16.24 & 5.75 \\
$95 \%$ Quantile & 53.10 & 34.90 & 20.00 & 9.20
\end{tabular}

Eigenvector

\begin{tabular}{|c|c|c|c|c|}
\hline & $\beta$ & $\mathbf{b}_{1}$ & $\mathbf{b}_{2}$ & $\mathbf{b}_{3}$ \\
\hline$i$ & 1.000 & -0.728 & -0.086 & -0.139 \\
\hline$e$ & -1.000 & 1.000 & -0.156 & -0.218 \\
\hline$g m$ & -2.015 & 3.366 & 1.000 & -9.487 \\
\hline$p$ & -1.175 & 2.035 & 0.041 & 1.000 \\
\hline Constant & 13.800 & -21.88 & -4.423 & 56.03 \\
\hline
\end{tabular}

Adjustment coefficient

\begin{tabular}{lrrrr}
\cline { 2 - 5 } & \multicolumn{1}{c}{} & \multicolumn{1}{c}{$\mathbf{a}_{1}$} & \multicolumn{1}{c}{$\mathbf{a}_{2}$} & \multicolumn{1}{c}{$\mathbf{a}_{3}$} \\
\hline$\Delta i$ & -0.939 & 0.171 & 1.048 & -0.009 \\
$\Delta e$ & -0.027 & -0.058 & 0.733 & 0.002 \\
$\Delta g m$ & 0.026 & 0.021 & -0.027 & 0.005 \\
$\Delta p$ & -0.050 & 0.034 & -0.012 & -0.009 \\
\hline
\end{tabular}

Note. "By $T$-nk" indicates the Reimers' (1992) small-sample correction by replacing $T$ by $T$ $n k$ in both $\lambda_{\max }$ and $\lambda_{\text {trace }}$ statistics, where $n$ is the dimension of the vector system and $k$ is the lag length in Model (1). The critical values are taken from Table 1 (case 1) in Osterwald-Lenum (1992).

moved along the supply possibilities frontier of bottleneck sectors and the distributive barrier between industrial expansion and needed agricultural growth, represented by the effective energy supply and per capita grain output, respectively. In other words, the binding constraints on the long-run level of real investment demand are these supply and distributive barriers. Another important implication of Eq. (4) is that it serves as a statistical expression for an equilibrium relationship among real investment, energy, and grain supplies. As a consequence, the error term, $\{i-p-e-2.0 \mathrm{gm}\}_{t-1}$, represents the previous disequilibrium and should be a powerful explanatory variable for the next direction of movement of $i_{t}$ or $(i-p)_{t}$. More concretely, when the error is positive (negative), $i_{t-1}$ and $(i-p)_{t}$ are too high (low) relative to the 

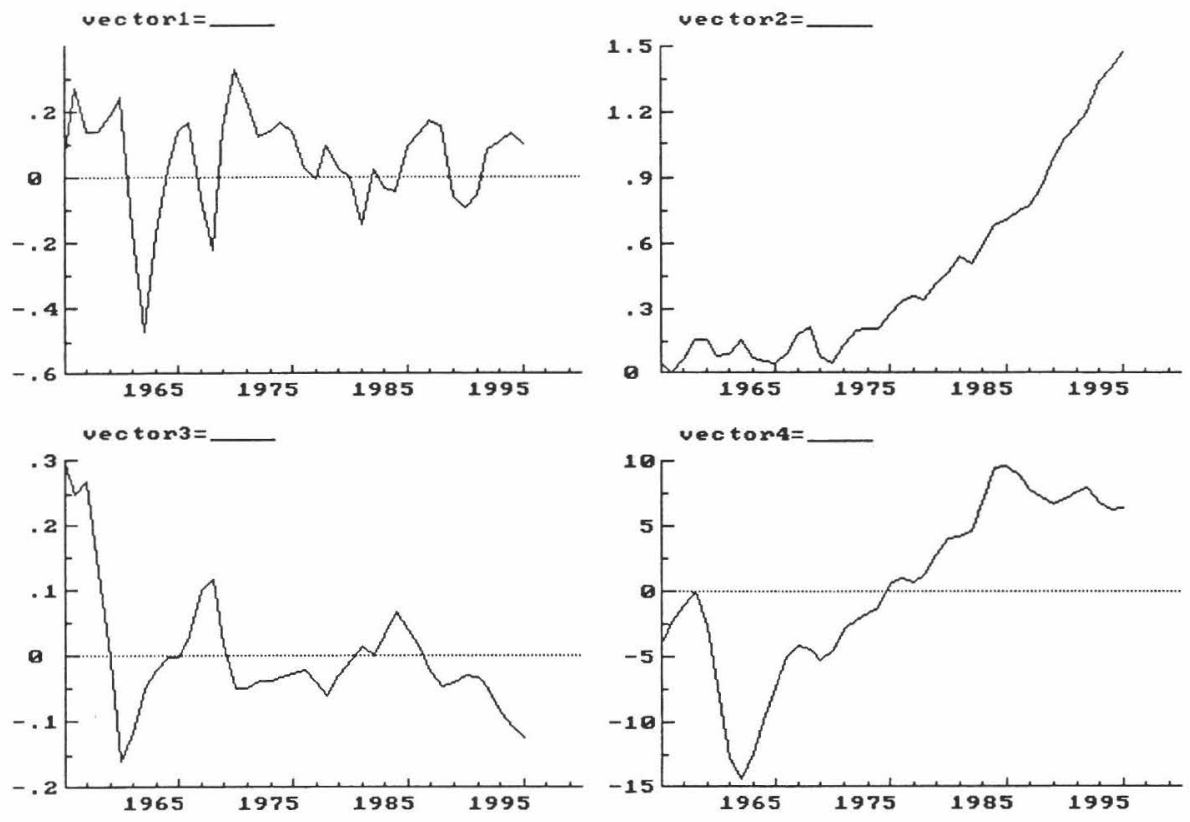

FIG. 1. The graphic tests for cointegration relations $\beta^{\prime}\left(Z_{t}^{\prime} 1\right)^{\prime}$. Vector 1 represents the relationship $\boldsymbol{\beta}^{\prime}\left(Z_{t}^{\prime} 1\right)^{\prime}$; vectors 2,3 , and 4 correspond to relationships $\mathbf{b}_{1}^{\prime}\left(Z_{t}^{\prime} 1\right)^{\prime}, \mathbf{b}_{2}^{\prime}\left(Z_{t}^{\prime} 1\right)^{\prime}$, and $\mathbf{b}_{3}^{\prime}\left(Z_{t}^{\prime} 1\right)$, respectively. Please refer to Eq. (2) and Table 1.

equilibrium comovement path and the economic agents will reduce (increase) $i$ in future periods relative to the comovement path.

The estimated adjustment coefficient vector $\alpha$ suggests that the disequilibrium error $\boldsymbol{\beta}^{\prime}\left(Z_{t}^{\prime} 1\right)^{\prime}$ has an important impact on $\Delta i$, while its influence on $\Delta e, \Delta g m$, and $\Delta p$ is less significant. This is confirmed by running Johansen's

\section{TABLE 2}

Tests for Linear Restriction on $\beta$ and Weak Exogeneity

\begin{tabular}{llll}
\hline Hypothesis $\left(H_{\mathrm{a}}\right)$ & $\operatorname{LR}\left(H_{\mathrm{a}}, H_{0}\right)$ & Hypothesis $\left(H_{\mathrm{a}}\right)$ & $\operatorname{LR}\left(H_{\mathrm{a}}, H_{0}\right)$ \\
\hline$\beta_{2}=-1.0\left(\beta_{1}=1.0\right)$ & $0.000(1.00)$ & $\alpha_{1}=0$ & $4.89(0.03)$ \\
$\beta_{3}=-2.0\left(\beta_{1}=1.0\right)$ & $0.003(0.95)$ & $\alpha_{2}=0$ & $0.06(0.81)$ \\
$\beta_{4}=-1.0\left(\beta_{1}=1.0\right)$ & $2.586(0.11)$ & $\alpha_{3}=0$ & $0.47(0.49)$ \\
$\beta=\left(1,-1,-2,-1,{ }^{*}\right)^{\prime}$ & $2.832(0.42)$ & $\alpha_{4}=0$ & $0.19(0.66)$ \\
& & $\alpha_{2}=\alpha_{3}=\alpha_{4}=0$ & $0.87(0.83)$ \\
\hline
\end{tabular}

Note. $\operatorname{LR}\left(H_{\mathrm{a}}, H_{0}\right)$ are Johansen and Juselius' (1992) LR statistics for testing $H_{\mathrm{a}}$ in $H_{0}: r=1$, asymptotically $\chi^{2}(3)$ distributed on the null of $\beta=\left(1,-1,-2,-1,{ }^{*}\right.$ )' and $\alpha_{2}=\alpha_{3}=\alpha_{4}=0$; and $\chi^{2}(1)$ distributed on the null of the others. "*" in $\beta$ means no restriction on the constant element. 
(1992b) LR tests of linear restrictions on $\alpha$. Table 2 also records these tests for the hypotheses $\alpha_{i}=0(i=1,2,3,4)$, where $\alpha_{i}$ is the $i$ th element of $\alpha$. As shown by Johansen (1992a) and Urbain (1992), $\alpha_{i}=0$ is equivalent to the $i$ th component of $Z_{t}$ being weakly exogenous for the long-run parameters in $\boldsymbol{\beta}$ as well as for the short-run parameters in the conditional equation. The test statistics in Table 2 show consistently that the weights of the cointegration relationship in the $\Delta e, \Delta g m$, and $\Delta p$ equations are not significantly different from zero, implying that energy, grain, and inflation are weakly exogenous in the system. Thus it becomes possible to construct a well-specified conditional investment growth equation based on Eq. (2) to capture fully the dynamics of investment determination represented in model (1).

\subsection{Investment Growth Rate Equation}

Based on the cointegration transformation that restricts $\Pi$ to equal $\boldsymbol{\alpha} \boldsymbol{\beta}^{\prime}$, model (2) becomes an $I(0)$ equation and can be estimated by OLS. After a subsequent simplification in order to obtain a more concise, yet congruent, data characterization, the results of estimation, with the usual standard errors, are reported in Table 3.

The goodness of fit measured by $R^{2}$ and $\hat{\sigma}$ is highly significant, and all of diagnostic statistics indicate that the investment growth rate equation is wellspecified. The overall parameter constancy of the conditional equation is confirmed by recursive estimation. Figure 2 shows the sequence of one-stepahead Chow tests, i.e., structural break test, none of which are significant. Figure 2 also records the one-step residuals and the corresponding \pm 2 standard errors to show that the standard error $\hat{\sigma}$ is almost constant over the sample. The constancy of each coefficient, except the $\Delta p_{t-1}$ 's, is also confirmed by the same recursive estimation; the relevant figures have been omitted here for simplicity. The recursive $t$ statistics for $\Delta p_{t-1}$ 's coefficient show that $\Delta p_{t-1}$ 's impact is dominated by the striking outlier after 1985 when the industrial price reform was initiated; before 1985 the impact was not significant statistically. Together these suggest that the equation is a well-specified and well-fitted investment growth rate equation with parameter constancy over the sample period (1953-1995).

The investment growth rate equation has a clear economic interpretation. First, the estimated coefficient of cointegration, i.e., error-correction term, reveals a large and significant adjustment to disequilibrium deviations of real investment levels from their normal level determined by the long-run investment function. In other words, on average, the investment agents decrease (increase) their real investment outlays by about $83 \%$ of the last year's over- (under-) investment. Second, notwithstanding this disequilibrium impact, the short-run bottleneck multipliers of effective energy supply for basic producer goods and grain output for basic consumer goods are significantly 
TABLE 3

The Estimation of an Investment Growth Rate Equation in China

Dependent variable: $\Delta(\mathrm{i}-\mathrm{p})_{t}$

\begin{tabular}{|c|c|c|}
\hline Explanatory variable & Coefficient & Standard error \\
\hline$\Delta(i-p)_{t-1}$ & 0.233 & 0.072 \\
\hline$\Delta e_{t}$ & 1.547 & 0.110 \\
\hline$\Delta g m_{t}$ & 2.311 & 0.424 \\
\hline$\Delta p_{t-1}$ & 1.154 & 0.277 \\
\hline$(i-p-e-2.0 \mathrm{gm})_{t-1}$ & 0.833 & 0.124 \\
\hline Constant & 11.437 & 1.696 \\
\hline Type of test & Test value & Probability \\
\hline$R^{2}$ & 0.90 & \\
\hline$\hat{\sigma}$ & 0.09 & \\
\hline DW & 1.86 & \\
\hline$F(5,35)$ & 65.70 & 0.00 \\
\hline Normality $\chi^{2}(2)$ & 0.42 & 0.81 \\
\hline AR $1-2 F(2,33)$ & 0.61 & 0.55 \\
\hline $\mathrm{ARCH} 1 F(1,33)$ & 0.06 & 0.82 \\
\hline Hetero $F(10,24)$ & 1.11 & 0.40 \\
\hline Functional form $F(20,14)$ & 1.24 & 0.34 \\
\hline Reset $F(1,34)$ & 1.63 & 0.21 \\
\hline
\end{tabular}

Note. $\hat{\sigma}$ is the estimated standard deviation of residuals. The normality $\chi^{2}(2)$ is the JarqueBera statistic. AR $i-j F(q, T-K-q)$ is the Lagrange Multiplier test for the $i$ th- to $j$ th-order residual autocorrelation $(q=j-i+1 ; T=$ the number of observations, and $K=$ the number of regressors in the equation). ARCH 1- $q F(q, T-K-2 q)$ is the $q$ th autoregressive conditional heteroscedasticity test. Hetero $F(q, T-K-q-1)$ is White's test for heteroscedasticity and tests the joint significance in a regression of the squared residuals on the regressors and their squares. Functional form $F(q, T-K-q-1)$ is a general test for functional form misspecification/heteroscedastic errors. RESET $F(q, T-K-q)$ is Ramsey's test for specification error. Probability in test-panel is the probability values of the test statistics under the relevant null hypothesis.

greater than zero; their values are quite close to the corresponding long-run multipliers in Eq. (4). Third, previous real investment growth does have a significant short-run inertia as discussed by Bauer (1978) and others, which is indeed consistent with certain characteristics of a socialist economy. Fourth, the significant positive correlation between $\Delta(i-p)$ and $\Delta p_{t-1}$ reflects the basic fact that, in a bureaucratically coordinated economy, an increase in the price level is not only a result of overinvestment but also, perhaps more significantly, a reason to request extra investment at least in the short-run because shifting the blame of extraexpenditure to rising input prices is straightforward and appears to be more reasonable (Kornai, 1992, pp. 548- 

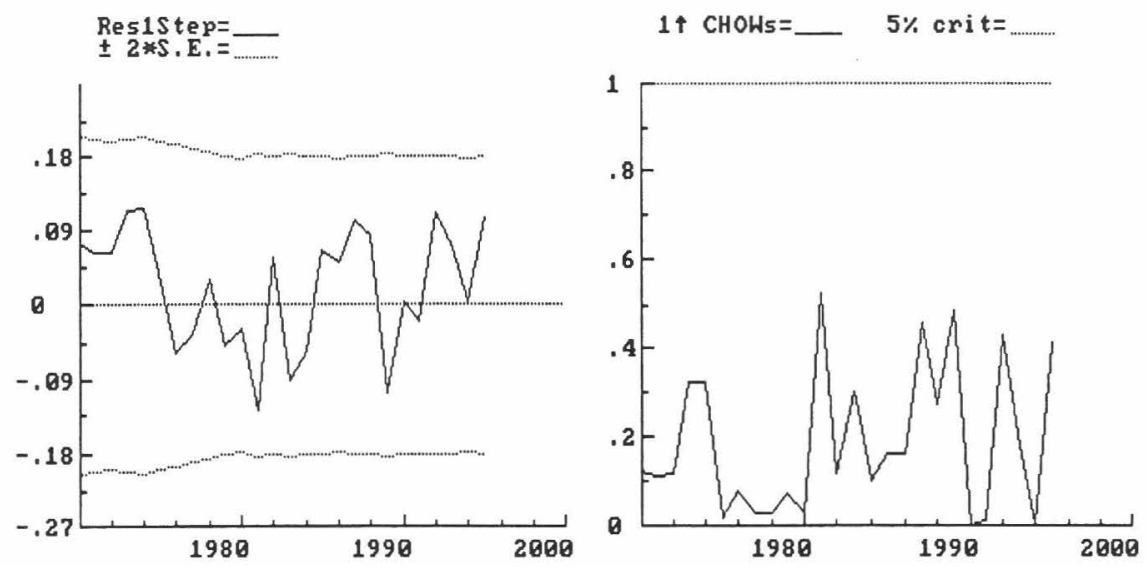

FIG. 2. One-step residuals, \pm 2 standard errors, and one-step-ahead Chow tests for the investment growth rate equation. Res lstep is the one-step residual; SE is the standard error. $1 \uparrow \mathrm{CHOW}$ is the one-step-ahead Chow test; $5 \%$ crit. is the normalized critical value at the $5 \%$ significant level.

552). This effect was relatively limited before reform but has played an increasingly important role during reform, as shown by the recursive $t$ statistics mentioned in preceding paragraph. The variable $\Delta p_{t-1}$ also represents a short-run shortage signal translated by the market component of the economy. However, the investment growth rate equation implies that this effect is overbalanced by the impact of offering a bargaining reason for requesting additional investment. Finally, the parameter constancy indicates that there is a lack of structural break induced by the reform.

The deeper constancy prevailing in the determination of the investment cycles does not imply that the concrete and immediate adjustment mechanism remains unchanged over time. Concrete adjustment processes can be quite different due to changing patterns in the distribution of power among different political groups and between the central and the local governments. The most significant change has taken place in the reforming years when inflation barriers played an increasingly important role in the investment adjustment process; this may make Kalecki's growth theory more relevant to China.

\section{CONCLUDING REMARKS}

Industrial accumulation and investment cycles are recurring subjects in the literature about socialist and developing economies. This paper advances the standard investment cycle theory of a socialist economy by introducing a new framework of growth cycle using the recently developed cointegration approach and incorporating the distributive barrier theory related to a typical dual developing economy. It is shown empirically that there is a persistent tension between system-generated investment ambitions and the supply and 
distributive barriers to ambitions for both pre- and postreform periods and in the presence of significant policy changes. As a result, the long-run investment function is characterized by equilibrium comovement among the real fixed investment level, grain output per capita as a proxy for necessary consumer goods, and effective energy supply per capita as a proxy for basic producer goods. Much of the cyclical pattern of the investment growth rate can be explained by the adjustment to the comovement path and by the relevant rates of change of energy supply and agricultural output. The fact that both functions maintain parameter constancy over the sample period indicates that there is a lack of structural break induced by the reform. This constancy, together with the surprising structural rigidity of the state industrial sector, may suggest that China's state investment system is still following its own logic and has not actively responded to the significant changes in demand occurring in a rapidly growing and transforming economy. Furthermore, the investment decision-making process is still dominated by bureaucratic negotiation based on vested sectoral interests and structural inertia, although the concrete mechanisms have changed.

The complicated bureaucratic coordination and bottleneck constraints have caused widespread investment inefficiency manifested as lasting and largescale duplication of construction at national level, initiation of too many new projects at the expense of technical updating of existing assets, greater prominence of gestation lags between the initiation and completion of investment projects, and in some projects having little value once their products face market demand and competition (cf., e.g., People's Daily, 26 April 1994; World Bank, 1994; Naughton, 1995). In order to eliminate the scourge of investment inefficiency, deeper reform of the state investment system is required. Reforming the state investment system involves several difficult issues, namely, tackling the problems of central-local relationships and the relationships among government, enterprises, and banks, solving the soft budget constraint of the state sector. These difficulties can be overcome gradually by reform strategies such as the denationalization of state enterprises and state banks, and market reinforced decentralization (Sun, 1989; World Bank, 1994; Montinola et al., 1995).

\section{APPENDIX: DATA SOURCES AND NOTES}

(i) Notations: Investment is fixed investment by state-owned units at current prices and in billion yuan. Grain is total output of grain in millions of tons. Energy is overall energy consumption in millions of tons of coal equivalents. Population is total population in millions. Price index is the price index of fixed investment by state-owned units. The grain output per capita and energy consumption per capita are expressed in kilograms.

(ii) Investment, grain, energy, and population data for 1951-1992 are 
taken directly from the Statistical Yearbook of China (Yearbook, hereafter, 1993, pp. 149, 364, 477, and 81) and for 1993-1995, data are from Yearbook (1994, p. 140; 1995, p. 138; 1996, pp. 140, 371, 203, and 69).

(iii) Price index: Since the official statistics for this index started only in 1989, we must find a proper proxy for it before 1989. Figures for 1952-1985 are the deflator of accumulation on fixed assets of state-owned units (AFAS). The deflator can be generated based on the ASAF's value series at current prices and an index series at comparative prices taken from Statistics on National Income: 1949-1985 (pp. 37 and 40). Because accumulation is the newly added fixed assets (less depreciation of the total fixed assets) plus the newly acquired circulating fund and the latter accounts for about only $25 \%$ of the total (Yearbook, 1993, pp. 76 and 48), we claim that this deflator is the best proxy for the price index of fixed investment by state sector in China's statistics. The most suitable proxy data for 1986-1988 are price indices of state-owned construction output values which were published after 1982 (Statistical Survey of China, 1987, p. 75; 1988, p. 73; 1990, p. 82; 1994, p. 89), because construction accounts for about $60 \%$ of the investment (Yearbook, 1993, p. 150). The figure for 1989 is from China Economic Yearbook (1990, pp. II-32). Data for 1990-1993 are from Economic Situation and Prospect of China, (1991-1992; pp. 202, 209; 1992-1993, p. 207; $1993-$ 1994, p. 3) and, for 1994 and 1995, data are from People's Daily (March 2, 1995, p. 2; March 5, 1996, p. 2).

\section{REFERENCES}

Bauer, Tamás, "Investment Cycle in Planned Economies." Acta Oeconomica 21, 3:243-260, Sept. 1978.

China Economic Yearbook 1990 (in Chinese). Beijing: Economic Yearbook Press, 1990.

China Information Daily. [in Chinese]

China Investment and Construction. [in Chinese]

Dickey, David A., and Fuller, Wayne A., "Distribution of the Estimators for Autoregressive

Time Series with a Unit Root," J. Amer. Statist. Assoc. 74, 366(1):427-431, June 1979.

Economic Situation and Prospect of China (Zhongguo jingji xingshi yu zhanwang) 1991-1992,

1992-1993, 1993-1994. Beijing: China Development Press, 1992, 1993, 1994.

Energy of China. [in Chinese]

Hendry, David F., and Mizon, Grayham, E., "Evaluating Dynamic Econometric Models by Encompassing the VAR."' In Peter C. B. Phillips, Ed., Models, Methods, and Applications of Econometrics: Essays in Honor of A. R. Bergstrom. Oxford: Blackwell, 1993.

Hussain, Athar, "Discussion on 'Energy Pricing for Sustainable Development in China., " In Ian Goldin and L. Alan Winters, Eds., The Economics of Sustainable Development, pp. 230-235. Cambridge: Cambridge Univ. Press.

Imai, Hiroyuki, “China's Endogenous Investment Cycle.” J. Comp. Econom. 19, 2:188-216, Oct. 1994.

Johansen, Soren, "Cointegration in Partial Systems and the Efficiency of Single-Equation Analysis." J. Econometrics, 52, 3:389-402, June 1992a.

Johansen, Soren, "Testing Weak Exogeneity and the Order of Cointegration in UK Money Demand Data." J. Policy Model. 14, 3:313-334, June 1992b. 
Johansen, Soren, and Juselius, Katarina, "Maximum Likelihood Estimation and Inference on Cointegration-With Applications to the Demand for Money." Oxford Bull. Econom. Statist. 52, 2:169-210, May 1990.

Johansen, Soren, and Juselius, Katarina, “Testing Structural Hypotheses in a Multivariate Cointegration Analysis of the PPP and the UIP for UK." J. Econometrics 53, 1-3:211-244, July-Sept. 1992.

Kalecki, Michal, Essays on Developing Economies. Sussex, U.K.: The Harvester Press, 1976.

Kornai, János, The Socialist System. Oxford: Oxford Univ. Press, 1992.

Liang, Weilie, "Rethinking and Analysis of the Energy Defect." Energy of China (Zhongguo Nengyuan) 2:6-9, Feb. 1989.

Lin, Justin Y., Cai, Fang, and Li, Zhou, The China Miracle: Development Strategy and Economic Reform. Hong Kong: The Chinese Univ. of Hong Kong, 1996.

Mihályi, Peter, Socialist Investment Cycles: Analysis in Retrospect. London: Kluwer Academic, 1992.

Montinola, Gabriella, Qian, Yingyi, and Weingast, Barry, R., “Federalism, Chinese Style: The Political Basis for Economic Success in China." World Politics 48, 1:50-81, Oct. 1995.

Naughton, Barry, "Macroeconomic Policy and Response in the Chinese Economy: The Impact of the Reform Process." J. Comp. Econom. 11, 3:334-353, Sept. 1987.

Naughton, Barry, Growing out of the Plan: Chinese Economic Reform, 1978-1993. Cambridge: Cambridge Univ. Press, 1995.

Osterwald-Lenum, Michael, "A Note with Quantiles of the Asymptotic Distribution of the Maximum Likelihood Cointegration Rank Test Statistics: Four Case.” Oxford Bull. Econ. Statist. 54, 3:461-471, Aug. 1992.

Peng, Fangchun, "Important Countermeasures for the Relaxation of the Current Shortage of Electricity." Energy of China (Zhongguo Nengyuan), 6:31-34, June 1989.

Perron, Pierre, "Trend, Unit Root and Structural Change in Macroeconomic Time Series." In B. Bhaskara Rao, Ed., Cointegration for the Applied Economist. London: Macmillan, 1994.

Reimers, Hans-Eggart, "Comparisons of Tests for Multivariate Cointegration." Statist. Papers (Berlin) 33, 4:335-359, Dec. 1992.

Sheng, Yuming, "The Capital Sources of China's Industrialization," Develop. Econom. 31, 2:173-207, June 1993.

Smil, Vaclav, Energy in China's Modernization: Advances and Limitations, London: Sharp., 1988.

(Survey) Statistical Survey of China. [Chinese versions] Beijing: China Statistics Press, 19871996.

(Yearbook) Statistical Yearbook of China. Beijing: China Statistics Press, 1991-1996.

Statistics on National Income: 1949-1985. Beijing: China Statistics Press, 1987. [in Chinese]

Sun, Laixiang, "The Special Contradictions in Our Economy and the Key Choices for Our Reform." Qiushi (Theoretical Journal of the Central Committee of CPC) 4:27-31, Feb. 1989.

Urbain, Jean-Pierre, “'On Weak Exogeneity in Error Correction Models." Oxford Bull. Econ. Statist. 54, 2:187-207, May 1992.

World Bank, China, The Energy Sector. Washington, DC: World Bank, 1985.

World Bank, China: Macroeconomic Stability in a Decentralized Economy. Washington, DC: World Bank, 1994.

Zhang, Jiwu, "Receive Lessons from the Seventh Five Years Plan Period, and Make Good Coordinative Development." Energy China (Zhongguo Nengyuan) 10:6-8, Oct. 1991.

Zou, Liang, and Laixiang, Sun, "Interest Rate Policy and Incentives of State-Owned Enterprises in the Transitional China." J. Comp. Econom. 23, 3:292-318, Dec. 1996. 
